\title{
Food safety at home: knowledge and practices of consumers
}

\author{
Elisa Langiano • Maria Ferrara • Liana Lanni • \\ Viviana Viscardi • Angela Marie Abbatecola • \\ Elisabetta De Vito
}

Received: 1 March 2011 / Accepted: 15 June 2011 /Published online: 1 July 2011

(C) The Author(s) 2011. This article is published with open access at Springerlink.com

\begin{abstract}
Aim To define food safety and risk perception of foodborne diseases in the private home setting and identify specific behaviours during food purchase, storage and preparation in a large survey study.

Subject and methods A large sample of individuals $(n=1,000)$ living in the area of Cassino, Italy, volunteered to participate in the study. All participants were randomly recruited and underwent a questionnaire-based interview at their home regarding food-safety measures. Logistic regres-
\end{abstract}

E. Langiano $\cdot$ M. Ferrara $\cdot$ L. Lanni $\cdot$ V. Viscardi $\cdot$ E. De Vito Department of Health and Sport Science, University of Cassino, Via Sant'Angelo, Località Folcara,

03043 Cassino, Italy

M. Ferrara

e-mail: m.ferrara@unicas.it

L. Lanni

e-mail: lianala@unicas.it

V. Viscardi

e-mail: vivivis@inwind.it

E. De Vito

e-mail: devito@unicas.it

A. M. Abbatecola

INRCA (Italian National Research Center on Aging)

Scientific Direction,

Via della Montagnola 81,

60125 Ancona, Italy

A. M. Abbatecola

e-mail: angela_abbatecola@libero.it

E. Langiano $(\bowtie)$

Dipartimento di Scienze Motorie e della Salute,

Università degli Studi di Cassino,

Via Sant'Angelo, Località Folcara,

03043 Cassino (Fr), Italy

e-mail: langiano@unicas.it sion analyses were used to test for correlations between demographic characteristics and knowledge/behaviours of food diseases. Risks of hazardous practices in the home were calculated according to educational, physical, occupational and marital status. All analyses were performed using the EPIINFO 3.5 statistical program.

Results Our data showed that there was an insufficient amount of knowledge regarding foodborne diseases and pathogens. In most families, we found that there was a lack of correct adherence to food hygiene, mainly due to errors during both food preparation and storage. There was a higher risk for food safety errors in families with children, older persons and pregnant women.

Conclusion Our findings confirm that the home environment represents an important site for the spread of pathogens responsible for foodborne diseases. In order to adopt good hygiene practices in the home setting, consumers need to be informed about safety procedures of domestic food handling, storage and preparation.

Keywords Food safety · Knowledge · Behaviours · Practices $\cdot$ Home $\cdot$ Consumers

\section{Introduction}

Even though there have been substantial developments in food production and safety management, developed countries continue to deal with numerous and critical food safety problems (Anklam and Battaglia 2001; International Commission on Microbiological Specifications for Foods 2006; Schlund 2002; Toyofuku 2006). In fact, despite the recent introduction of careful legislation and improvement on food production and storage techniques, foodborne diseases represent significant concerns for the economic 
consequences of public health (Adak et al. 2005; Buzby and Roberts 2009; De Giusti et al. 2007; Doménech et al. 2007; Faustini et al. 2003; Hoffman et al. 2005; Kim 2009; Meng and Doyle 1998; Meng and Doyle 2002).

Since 1980, the World Health Organization (WHO) Food Surveillance Programme for the Control of Foodborne Diseases has been working with the Food and Agriculture Organization (FAO) (Tirado and Schmidt 2001) to continuously provide updates on food-related epidemics in European countries and substantial support to national authorities on improving, preventing and controlling foodborne illnesses. In addition, during the year 2002, food quality and health-policy measures were established by the European Food Safety Authority (EFSA) in Parma, Italy. In Italy, foodborne diseases are regarded as infectious diseases; however, data related to these diseases are often inaccurate and untimely. Therefore, the national surveillance system, Enter-net Italia, coordinated by the Istituto Superiore di Sanità (ISS) has activated numerous laboratories dedicated to study investigations in the medical, veterinary and environmental fields (Istituto Superiore di Sanità 2007).

It has been widely demonstrated that the private home setting is considered the first place in which foodborne diseases develop due to poor personal and/or environmental hygiene with an increased risk of infection (Istituto Superiore di Sanità 2003; Comodo et al. 2000; Fara and Proietti 2000; Griffith et al. 1998; Istituto Superiore di Sanità 2006; Kagan et al. 2002; Redmond and Griffith 2003; Scott 2001). According to WHO, over $30-40 \%$ of foodborne disease cases occur in the home and in Italy, approximately 30,000 cases/year have been observed: (55$75 \%$ due to outbreaks and $25-40 \%$ attributable to homemade preparation) (Istituto Superiore di Sanità 2006). Foodborne diseases are progressively increasing and the number of reported cases are underestimated due to the lack of outbreak reports in the home setting (Redmond and Griffith 2003; Tauxe 2002; Istituto Superiore di Sanità 2003).

At the moment, most purchased foods are considered safe; however, there still remains the need for consumers to correctly preserve these food items. Indeed, consumers represent the final step for food preparation and prevention of foodborne illnesses (Kagan et al. 2002; Redmond and Griffith 2003). In order to adopt good hygiene practices in the home setting, it is necessary to reduce the risk of improper food handling and storage. At the moment, there is a lack of literature regarding consumer behaviour in the home. Therefore, we aimed at investigating food-safety knowledge and the risk perception of foodborne diseases in the private home as well as, characterize their behaviours during food purchase, storage and preparation through the use of an interview-based questionnaire in a large sample of individuals.

\section{Methods}

A cross-sectional study of consumer food-safety knowledge and practices was performed from January and April 2008 in a large sample of individuals living in the area of Cassino, a town in Latium (central Italy). Researchers from the laboratory of Hygiene at the University of Cassino, Italy, used information from the official address registry of the city of Cassino to randomly recruit participants. In all, participants who agreed to enrol in the study protocol, a survey was conducted using questionnaire based interview at the private home of each participant.

Data collection was carried out in two consecutive phases. In the first phase, qualitative data were collected through "one-on-one" interviews from a sample of 50 families to identify specific focal points needed for the development of the questionnaire of the second phase of the protocol. The second phase was carried out on a sample of 1,000 families, using the developed questionnaire performed at the home of each participant. Interviews were performed by trained researchers or students from the laboratory of Hygiene at the University of Cassino. The protocol included adults (18 years or older) responsible for food preparation in the household. All answers to closed and open questions were written down manually by the interviewer. The time to complete an interview was approximately $45 \mathrm{~min}$ and interviews were performed during weekends and weekday afternoons. The research coordinator assessed the accuracy of the data collection forms and the procedure standardizations regularly.

\section{The questionnaire}

The questionnaire was tested and fully developed from November to December 2008. A four-page questionnaire was developed and free text answers were minimal. Most of the questions were structured in check box (often/always/ sometimes/never) or in a defined set of possible answers. The questionnaire consisted of 48 closed and open questions, divided into different themes and grouped in five sections as follows:

1. Socio-demographic section: age, sex, marital status, educational level, occupation, the number of family members, the presence in the household of children or other persons such as elderly persons, pregnant women, immunosuppressed or cancer patients, drug addicts, not self-sufficient

2. Food safety knowledge section to define the individual knowledge of the causes related to food spoilage and foodborne diseases

3. Suspected food poisoning section: to estimate from interviewer experience information related to symptoms 
occurring within a few hours following suspected contaminated food ingestion, including the member of the family that had symptoms, behaviours adopted, and where food was purchased

4. Food safety practices (purchasing, handling, storage) for the determining habits during these three important moments of food safety

5. Home food-safety needs section for identifying needs of the respondents regarding food safety in the home

\section{Statistical analysis}

Statistical analyses were performed using the statistical program EPIINFO 3.5 version. The $\chi^{2}$ test was applied to test for differences among variables, and probability value less than 0.05 was considered statistically significant. Contingency tables were used to verify the relationship between some socio-demographic data (marital status, educational level and profession) and habits (place of purchase, control of products before purchase, etc.). Logistic regression models with foodborne disease as the dependent variable were used to test for independent associations between age range (18-29 years, as reference group, 30-39, 40-49, $\geq 50$ ) gender (men as reference group), marital status (married as reference group, single, separated, divorced), level of education (elementary, middle school, high school as reference group, college degree), occupation (blue collar worker, white collar worker as reference group, housewife) and those at risk (pregnant women, children and elderly). Such models were used to identify the influence of demographic data on the knowledge (main causes of food spoilage, microorganisms responsible for foodborne diseases), on the behaviours (food storage) and on detecting at risk categories. The results are expressed as odds ratio (OR) and confidence intervals of $95 \%$ (CI 95\%).

\section{Results}

A total of 624 analyzable questionnaires were obtained, with a response rate of $62.4 \%$.

\section{Demographic section}

Demographic data including gender, age, marital status, educational background and occupation are shown in Table 1 . We found that $38.3 \%$ had children with a mean age of $9.8 \pm 6.3$ years: 1 child $(21 \%), 2$ children $(15 \%)$ or 3 children (2.6\%). Households included $17.1 \%$ elderly persons (mean age of $75.5 \pm 7.6$ years), $4.8 \%$ not self

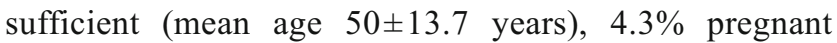

women (mean age of $30 \pm 11.1$ years, $0.6 \%$ immunosuppressed (mean age $41.2 \pm 28$ years), $0.6 \%$ with cancer (mean age $44.3 \pm 13.0$ years and $0.3 \%$ with drug addicts (mean age of $24.5 \pm 9.1$ years).

\section{Food safety knowledge}

Overall we found that $39.9 \%$ were aware of the role played by microorganisms, $26.4 \%$ by the role of temperature and only $5.0 \%$ knew about the importance of temperature and light. These data were stratified according to age, gender, marital status, educational level and occupation (Table 2). Women were more aware of the definition of foodborne diseases, but an overall $42.1 \%$ were unable to define foodborne diseases and considered that these diseases were caused by ingestion of spoiled or expired food $(27.0 \%)$ or by infection from salmonella, botulism and hepatitis A (30.4\%). Also, the effects of foodborne pathogens on foods were not well-known: $44.6 \%$ believed that altered organoleptic characteristics of foods were due to smell $(13.5 \%)$, flavor $(13.6 \%)$ or colour $(5.4 \%)$. $66.7 \%$ believed that microorganisms contaminated foods during production or during the storage process with significant differences according to gender, marital status, educational level and type of occupation (Table 2).

\section{Suspected food poisoning}

Reported symptoms occurring within a few hours following contaminated food ingestion included: diarrhea (34.8\%), abdominal cramping (27.5\%), vomiting $(24.7 \%)$ and fever $(8.3 \%)$. These symptoms were more frequent in the mother (44.8\%), followed by the child $(30.1 \%)$ and lastly by the father $(15.4 \%)$. Foods considered responsible for food poisoning were altered milk and/or milk products $(24.8 \%)$, vegetables $(18.2 \%)$, sweets $(12.4 \%)$, seafood $(11.7 \%)$, meat (7.3\%), eggs $(3.6 \%)$, and other $(16.8 \%)$. Such foods were mainly purchased at supermarkets, discount stores or minimarkets (50\%), followed by pastry shops and bars (11.5\%), and fish markets and restaurants (7.7\%). Behaviours adopted for foodborne disease symptoms were: $34.2 \%$ self cure (using over-the-counter drugs) $25.9 \%$ medical assistance; $16.8 \%$ no assistance (waited for symptoms to subside); $2.4 \%$ had laboratory blood work; $1.0 \%$ required hospital care.

Food safety practices

Food was mainly purchased by the mother $(51.4 \%)$, by both parents $(29.5 \%)$, child alone $(5.9 \%)$ or father alone (4.2\%). The supermarket/shopping center was used by more than half of the sample (65.3\%) especially by married couples followed by singles, widowers and unmarried partners. This result did not exclude the choice of discount 
Table 1 Descriptive characteristics of the study population

\begin{tabular}{|c|c|c|c|c|c|c|}
\hline & \multicolumn{2}{|c|}{ Total sample size } & \multicolumn{2}{|l|}{ Male } & \multicolumn{2}{|l|}{ Female } \\
\hline & $n$ & $\%$ & $n$ & $\%$ & $n$ & $\%$ \\
\hline \multirow[t]{2}{*}{ Sample size } & 624 & 100 & 77 & 100 & 547 & 100 \\
\hline & & 100 & & 12.3 & & 87.7 \\
\hline Mean age \pm SD & $41.3 \pm 12.2$ & & $36.9 \pm 11.3$ & & $41.9 \pm 12.1$ & \\
\hline \multicolumn{7}{|l|}{ Age group } \\
\hline $18-29$ & 130 & 20.8 & 37 & 48 & 93 & 17 \\
\hline $30-39$ & 157 & 25.2 & 12 & 15.6 & 145 & 26.5 \\
\hline $40-49$ & 170 & 27.2 & 16 & 20.8 & 154 & 28.2 \\
\hline $50-59$ & 117 & 18.8 & 9 & 11.6 & 108 & 19.8 \\
\hline$>60$ & 46 & 7.4 & 2 & 2.7 & 44 & 8 \\
\hline Missing & 4 & 0.6 & 1 & 1.3 & 3 & 0.5 \\
\hline \multicolumn{7}{|l|}{ Marital status } \\
\hline Single & 105 & 16.7 & 27 & 35.1 & 78 & 14.3 \\
\hline Married/co-living & 470 & 75.4 & 37 & 48 & 433 & 79.1 \\
\hline Separated & 34 & 5.5 & 11 & 14.3 & 23 & 4.2 \\
\hline Widowed & 10 & 1.6 & 0 & 0 & 10 & 1.8 \\
\hline Missing & 5 & 0.8 & 2 & 2.6 & 3 & 0.6 \\
\hline \multicolumn{7}{|l|}{ Educational level } \\
\hline Primary school & 45 & 7.2 & 3 & 3.9 & 42 & 7.7 \\
\hline Junior high school & 139 & 22.3 & 20 & 26.3 & 119 & 21.8 \\
\hline High school & 345 & 55.3 & 48 & 63.2 & 297 & 54.3 \\
\hline College degree & 90 & 14.4 & 6 & 6.6 & 84 & 15.3 \\
\hline Missing & 5 & 0.8 & 0 & 0 & 5 & 0.9 \\
\hline \multicolumn{7}{|l|}{ Work activity } \\
\hline White-collar worker & 145 & 23.2 & 22 & 28.6 & 123 & 22.6 \\
\hline Housewife & 127 & 20.3 & 0 & 0 & 127 & 23.1 \\
\hline Blue-collar worker & 71 & 11.4 & 19 & 24.7 & 52 & 9.5 \\
\hline Teacher & 44 & 7.0 & 1 & 1.3 & 43 & 7.9 \\
\hline Student & 43 & 6.9 & 7 & 9.1 & 36 & 6.6 \\
\hline Dealer & 38 & 6.1 & 8 & 10.4 & 30 & 5.5 \\
\hline Self employed & 33 & 5.3 & 4 & 5.2 & 29 & 5.3 \\
\hline Craftsman & 29 & 4.6 & 2 & 2.6 & 27 & 4.9 \\
\hline Farmer & 13 & 2.1 & 5 & 6.4 & 8 & 1.5 \\
\hline Unemployed & 19 & 3.1 & 2 & 2.6 & 17 & 3.1 \\
\hline Retired & 19 & 3.1 & 3 & 3.9 & 16 & 2.9 \\
\hline Other & 25 & 4.0 & 2 & 2.6 & 23 & 4.2 \\
\hline Missing & 18 & 2.9 & 2 & 2.6 & 16 & 2.9 \\
\hline \multicolumn{7}{|c|}{ Number of persons in household } \\
\hline 1 & 57 & 9.1 & - & - & - & - \\
\hline $2-5$ & 534 & 85.6 & - & - & - & - \\
\hline$>6$ & 22 & 3.6 & - & - & - & - \\
\hline Missing & 11 & 1.7 & - & - & - & - \\
\hline
\end{tabular}

stores $(12.9 \%)$, which was particularly used by younger adults aged between 25 and 50 years of age (64.4\%). There were statistically significant differences based on gender, marital status, educational level and occupation as reported in Tables 3 and 4.
Grocery shopping was preferred on a weekly basis in $47.3 \%$, while on a daily basis in $39.1 \%$ in the following types of stores: convenience $(46.6 \%)$, comfort $(31.2 \%)$, hygiene $(26.5 \%)$, reliable retailer $(25.5 \%)$, fresh produce (15.9\%). Approximately $30 \%$ preferred foods produced 
Table 2 Bivariate analysis and logistic regression analyses testing the correlations between social-demographic factors and knowledge/behaviours of foodborne diseases

$\% \quad P$ value $\quad$ OR $\quad 95 \%$ CI $\quad P$ value

The main causes of food spoilage:

Microrganisms

Age group total sample (30-39 vs. 18-29)

$\begin{array}{ll}25.9 & 0.0009 \\ 24.5 & 0.01 \\ 32.6 & 0.9 \\ 82.4 & 0.0001 \\ 64.0 & 0.0001 \\ & \\ 61.7 & 0.0001 \\ 28.6 & 0.0001 \\ & \\ 84.1 & 0.0001 \\ 68.3 & 0.0001 \\ 51.2 & 0.0001\end{array}$

Age group female (30-39 vs. 18-29)

Age group male (30-39 vs. 18-29)

Gender (female vs. male)

$\% \quad P$ value

OR $\quad 95 \% \mathrm{CI} \quad P$ value

Marital status (married vs. single)

Married (ref.)

Educational level (high school vs. junior high school)

Work activity (white-collar worker vs. blue-collar worker)

Temperature

Gender (female vs.male)

Marital status (married vs. single)

Educational level (high school vs. junior high school)

Light

Marital status

Married

Single (ref.)

Educational level

Junior high school

High school (ref.)

Definition of foodborne diseases

0.0001

Gender (female vs. male)

$75.0 \quad 0.0001$

The microrganisms which causes foodborne diseases:

Maintain organoleptic characteristics

Gender (female vs. male)

$89.7 \quad 0.0001$

Marital status (married vs. single)

$78.0 \quad 0.02$

Educational level (high school vs. junior high school)

$48.3 \quad 0.03$

Work activity (housewife vs. blue-collar worker)

$28.6 \quad 0.000$

Housewife $\quad 0.5 \quad 0.2-0.9 \quad 0.006$

Alter the organoleptic properties

Educational level

Junior high school

High school (ref.)

Blue-collar worker

White-collar worker (ref.)

White-collar worker (rif)

Single $\quad 1.7 \quad 1.3-7.8 \quad 0.007$

1

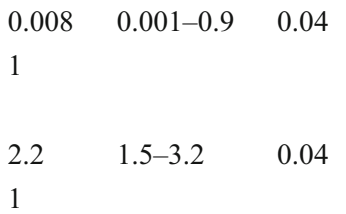

Are present during production or storage

Marital status (married vs. single)

$72.7 \quad 0.0001$

$\begin{array}{llll}\text { Educational level (high school vs. junior high school) } & 63.6 & 0.0003\end{array}$

$\begin{array}{lll}\text { Work activity (white-collar worker vs. blue-collar worker) } & 45.5 & 0.0001\end{array}$

Are not present if the food is contaminated during production or storage

Marital status

Single

$2.7 \quad 2.4-8.4 \quad 0.04$

Married (ref.)

$2.4 \quad 1.5-3.4 \quad 0.009$

Work activity

Blue-collar worker

1

$3.1 \quad 2.6-5.2 \quad 0.01$

White-collar worker (ref.) 
from specific geographical Italian regions. Purchasing fruits and vegetables at roadside venders was occasionally practiced in $44.7 \%$ of the study sample, essentially by those with a secondary-school level or blue-collar workers with a lower level of education. During food purchases, women, married couples, recent graduates and white collar workers reported to always control the expiration date (Tables 3 and 4). Other important factors were integrity of the package, price and appearance of food. Moreover, married couples and housewives were influenced by the brand name. In regards frozen foods, $62.2 \%$ expressed concern for signs of defrost-refroze, $59.3 \%$ for package integrity, while $12.3 \%$ were confident in the brand name and $10.4 \%$ in retailer. $56.2 \%$ did not control the freezer temperature and $35.4 \%$ reported to transport frozen foods in thermal containers after their purchase, especially women $(93.6 \%, p<0.01)$ and married couples $(76.7 \%, p<0.01)$. Raw eggs were purchased at supermarkets/ minimarkets in $41.3 \%$, while $34.6 \%$ produced their own eggs and $19.9 \%$ bought directly from farmers.

Responses regarding canned foods highlighted that respondents had found at least once a bended can $(51.8 \%)$, cans with rust $(21.6 \%)$, swelling $(20.4 \%)$, presence of mould and insects $(6.6 \%)$ after purchase. A total of $20.6 \%$ did not inform the grocer in case of such defects.
Commonly observed risky behaviours during food purchase are presented in Table 5.

\section{Food handling in the home}

We found that it was highly common to defrost meat and fish at room temperature (62.7\%) compared to defrosting in the refrigerator $27.2 \%$ (Table 5), especially among recent high school graduates $(53.3 \% ; p<0.05)$ and housewives $(24.1 \% ; p<0.01)$. Almost all participants $(93.4 \%)$ respected storage times listed on frozen foods packages.

We also found that $24.0 \%$ of cooked foods were stored in the refrigerator after cooling to room temperature, while $28.0 \%$ were stored in the refrigerator within 24 hours if not consumed. Responses regarding the most important rules related to refrigerator use included: avoiding frequent opening of the refrigerator $(64.1 \%)$ and not placing the refrigerator near heat sources (36.4\%). In all, $22.3 \%$ reported that their refrigerator was over full and $20 \%$ regularly checked refrigerator bins.

Food was generally stored in sealed containers in the refrigerator $(40.9 \%)$ in free spaces $(39.4 \%)$; direct contact between cooked and raw foods was only avoided in $36.5 \%$ indicating the unawareness of the risk of cross contamina-
Table 3 Respondent's behaviour when purchasing food

\begin{tabular}{|c|c|c|c|c|}
\hline & $\%$ & $\%$ & $\%$ & $\%$ \\
\hline Where the purchase was made & Always & Often & Sometimes & Never \\
\hline Supermarket & 65.3 & 26.3 & 6.8 & 1.6 \\
\hline Small distribution & 17.2 & 19.8 & 19.5 & 43.5 \\
\hline Market & 11.5 & 16 & 22.7 & 49.8 \\
\hline Discount & 12.9 & 12.2 & 17.5 & 57.4 \\
\hline Home sales & 0.2 & 2.2 & 4.3 & 93.3 \\
\hline \multicolumn{5}{|l|}{ Used purchasing controls for } \\
\hline Appearance & 46.9 & 9.4 & 5.6 & 38.1 \\
\hline Package integrity & 53.9 & 7.8 & 4 & 34.3 \\
\hline Expiration date & 84 & 9.5 & 3 & 3.5 \\
\hline Label & 34.3 & 14.5 & 10.8 & 40.5 \\
\hline Price & 46 & 18 & 10.6 & 25.4 \\
\hline Brand & 21.7 & 11.9 & 14 & 52.4 \\
\hline Label control & yes & & & \\
\hline Ingredients & 32.7 & - & - & - \\
\hline Expiration date & 76 & - & - & - \\
\hline Calories & 18.6 & - & - & - \\
\hline Ntritional composition & 19.1 & - & - & - \\
\hline \multicolumn{5}{|l|}{ Choice of store } \\
\hline Confidence in the retailer & 25.5 & - & - & - \\
\hline Comfort of the store & 31.4 & - & - & - \\
\hline Price & 46.6 & - & - & - \\
\hline Food quality & 66.5 & - & - & - \\
\hline Store hygiene & 26.5 & - & - & - \\
\hline
\end{tabular}


Table 4 Bivariate analysis of social demographic factors to consumer behaviour

\begin{tabular}{lll}
\hline & $\%$ & $P$ value \\
\hline Food purchased at: & & \\
Supermarket/shopping center & 77.8 & 0.0001 \\
Marital status (married vs. single) & & 0.0001 \\
Discount & 79.3 & 0.0001 \\
Gender (female vs. male) & 55.9 & 0.0001 \\
Educational level (junior High school vs. College Degree) & 23.7 & 0.0001 \\
Work activity (Housewife vs. Self employed) & 62.7 & 0.0001 \\
Marital status (married vs. single) & & \\
Fruit purchasing from roadside vendors & 44.4 & 0.05 \\
Educational level (Junior High school vs. College Degree) & 22.2 & 0.04 \\
Work activity (Blue collar worker vs. White collar worker) & & \\
Control "sell-by date" during purchase & 89.9 & 0.002 \\
Gender (female vs. male) & 72.6 & 0.003 \\
Marital status (married vs. single) & 56.6 & 0.003 \\
Educational level (High school vs. Junior High school) & 26.0 & 0.002 \\
Work activity (Blue collar worker vs. White collar worker)
\end{tabular}

tion (Table 5). The most correct behaviours were among graduates $(52.2 \% ; p<0.01)$, housewives $(36.2 \% ; p<0.01)$ and married couples $(70.9 \% ; p<0.01)$.

During the interview, participants were also asked to indicate if meat and fish were considered undercooked at the time of consumption. In all, 9.8\% considered meat and $6.9 \%$ considered fish undercooked (Table 5). In married couples vs. singles, we found 47.5 vs. $39 \%$ for undercooked meat $(p<0.01)$ and 44.2 vs. $39.5 \%$ for undercooked fish $(p<0.05)$.

After handling raw meat, $64.5 \%$ reported to always cleanse hands with soap and water, $31.8 \%$ with water alone and $1.9 \%$ with only a hand towel. Similarly $84.9 \%$ reported to cleanse hands with soap and water after handling raw fish compared to the $7.3 \%$ who washed with water only or the $1.1 \%$ who only used a towel (Table 5 ). The survey showed that raw fish was gutted, washed and stored in a refrigerator before cooking in $14.9 \%$, especially by singles $(82.9 \%$; $p<0.01$ ), while eggs were stored at room temperature in $23.9 \%$ of all households. During food preparation, $78.7 \%$ affirmed using the same cutting board for raw and cooked foods. Wood cutting boards were preferred over plastic ones (76.3 vs. $23.7 \%$; Table 5). Prior to consumption, food was mainly prepared and cooked immediately in $63 \%$-vs. several hours before $(28.5 \%)$, vs. a few days prior $(14.1 \%)$.

Logistic regression models confirmed that high-risk behaviours of improper safety rules were influenced by socio-demographic factors, including a low education level,
Table 5 Inappropriate practices during food purchase, preparation and storage

\begin{tabular}{lll}
\hline & $\%$ & $95 \%$ CI \\
\hline Inappropriate practices during food purchase & & \\
No control of the food packaging & 34.2 & $30.1-38.6$ \\
No control of frozen food packaging & 40.7 & $36.8-44.7$ \\
No label control & 40.4 & $36.0-44.9$ \\
Conservation of frozen or refrigerated food in cool bags & 40.1 & $35.8-44.6$ \\
Inappropriate practices in the home & & \\
Undercooked meat consumption & 9.8 & $7.6-12.5$ \\
Undercooked fish consumption & 6.9 & $5.1-9.3$ \\
Hand-washing with water after handling raw meat & 31.8 & $27.4-36.5$ \\
Hand-washing with water after handling raw fish & 7.3 & $3.9-11.2$ \\
Storage at room temperature & 24.0 & $20.8-27.6$ \\
Defrosting at room temperature & 62.7 & $58.7-66.4$ \\
Close contact of raw and cooked foods in the refrigerator & 63.5 & $59.5-67.2$ \\
Using the same chopping board to prepare raw and cooked foods & 78.7 & $75.3-81.7$ \\
Using wooden chopping board & 76.3 & $72.7-79.5$ \\
\hline
\end{tabular}


single status, students living far from their families and bluecollar workers (Table 6). There were also food safety errors in families that included a high-risk group for food poisoning like children, elderly and pregnant women (Table 6).

Requested information

A high percentage of respondents (79.2\%) were aware of their lack of knowledge regarding food safety and 37.8\% expressed interest in obtaining information from nutrition experts, $29.9 \%$ from the mass media and $15.5 \%$ from informative brochures. However, only $34.1 \%$ responded that they would attend a daily seminar. This low response may be explained by education and occupational level (elementary graduate $84.1 \%, p<0.01$; housewives $72.5 \%$, $p<0.05)$.

\section{Discussion}

Using a questionnaire-based interview on food safety practices in the home, our findings highlight the need to improve basic knowledge on foodborne diseases transmissions and the behaviours necessary to reduce this risk. Many reports have evaluated consumer knowledge on foodborne illness agents, attitudes, practices, hygiene behaviours during food preparation and the role of the home environment in relation to these infections (Angelillo et al. 2001; Hillers et al. 2003; Istituto Superiore di Sanità 2006; Kagan et al. 2002; Redmond and Griffith 2003; Scott 2001; Unusan 2007). Our survey showed that the lack of knowledge on foodborne diseases and pathogens was linked to the microbiology of foodborne pathogens which in turn affect safe food storage, preparation, and cooking
Table 6 Logistic regression analyses testing the correlations between risks of hazardous practices in the home according to marital status, educational level and work activity and in groups at risk

\begin{tabular}{|c|c|c|c|}
\hline & OR & $95 \% \mathrm{CI}$ & $P$ value \\
\hline \multicolumn{4}{|c|}{ Food defrost at room temperature } \\
\hline \multicolumn{4}{|l|}{ Demographic data } \\
\hline \multicolumn{4}{|l|}{ Educational level } \\
\hline Junior high school & 3.8 & $2.6-4.9$ & 0.007 \\
\hline High school (ref.) & 1 & & \\
\hline \multicolumn{4}{|l|}{ Work activity } \\
\hline Blue-collar worker & 1.7 & $1.5-2.9$ & 0.02 \\
\hline White-collar worker (ref.) & 1 & & \\
\hline \multicolumn{4}{|l|}{ Risk categories } \\
\hline \multicolumn{4}{|l|}{ Pregnant women } \\
\hline Yes & 4.2 & $1.6-11.06$ & 0.003 \\
\hline No (ref.) & 1 & & \\
\hline \multicolumn{4}{|l|}{ Elderly } \\
\hline Yes & 1.4 & $1.2-4.6$ & 0.04 \\
\hline No (ref.) & 1 & & \\
\hline \multicolumn{4}{|l|}{ Children } \\
\hline Yes & 1.9 & $1.7-4.9$ & 0.02 \\
\hline No (ref.) & 1 & & \\
\hline \multicolumn{4}{|c|}{ Cooked foods not consumed immediately conserved at room temperature } \\
\hline Single & 4.1 & $3.5-7.5$ & 0.006 \\
\hline Married (ref.) & 1 & & \\
\hline \multicolumn{4}{|l|}{ Work activity } \\
\hline Housewife & 0.3 & $0.08-0.9$ & 0.03 \\
\hline Blue-collar worker & 1.6 & $1.1-3.1$ & 0.007 \\
\hline White-collar worker (ref.) & 1 & & \\
\hline \multicolumn{4}{|l|}{ Storage at room temperature } \\
\hline \multicolumn{4}{|l|}{ Pregnant women } \\
\hline Yes & 2.9 & $1.1-7.1$ & 0.02 \\
\hline No (ref.) & 1 & & \\
\hline \multicolumn{4}{|l|}{ Elderly } \\
\hline Yes & 1.7 & $1.5-5.9$ & 0.03 \\
\hline No (ref.) & 1 & & \\
\hline
\end{tabular}


procedures (Redmond and Griffith 2003). In accordance with other studies, we found that women aged 30-39 years, were more likely to be better informed than men (Angelillo et al. 2001; Unusan 2007).

The families in this study consisted of various members including those at a higher risk for the acquisition of foodborne disease such as young children, pregnant women, elderly, disabled persons and immune-compromised individuals. Thus, our data highlight the importance for better food safety measures in the home with numerous members (Hillers et al. 2003; Oldfield 2001; Scott 2001; Scott 2001; Tauxe 2002).

As expected, we found that symptoms began after the ingestion of contaminated food and did not usually require medical assistance which is in agreement with evidence showing that the majority of foodborne infections are mild, with diarrhoea or other self-limiting symptoms. This information confirms that foodborne diseases are more frequent than those reported due to disease-related mild symptoms and, thus do not reflect the real situation (Redmond and Griffith 2003; Tauxe 2002; Unusan 2007). Consumers need to be informed about the severity of foodborne diseases and the importance of consulting their general practitioner in the presence of gastrointestinal symptoms immediately following food ingestion, especially elderly, children, pregnant women, and immune-compromised individuals.

It was difficult to identify microbiological hazards during food purchase because of the large range of measures adapted by participants without any form of proper training. In the absence of objective information, we found that most participants relied on indirect clues, like the appearance when judging food safety which was also found in a previous study (Grunert 2002). Consumers need to obtain necessary information for applying practical measures during food purchase which will significantly impact better decision-making. Consumers also need to be aware of practices that are potentially hazardous when purchasing foods.

Although product traceability is mandatory for tracking product origin, our survey showed that participants considered the brand name to be more important. Similar behaviour has been observed in another European investigation on consumer behaviour towards food safety risks and information (Verbeke et al. 2007).

Correct food handling and storage procedures are essential measures for assuring food safety in the home. Unfortunately, we observed numerous factors related to the onset of foodborne illnesses due to inappropriate food safety practices (Tables 4 and 5). In most families, there was a lack of correct adherence to food hygiene during both food preparation and storage measures. Improper food storage, undercooking and cross-contamination were spe- cific risk factors for domestic outbreaks of foodborne pathogens which may be responsible for $30 \%$ of all salmonella outbreaks in the home (Kagan et al. 2002). A review by Redmond and Griffith (2003) analyzing 88 consumer safety studies, underlined that unsafe foodhandling practices are still commonly found during the preparation of food in private homes, thus increasing the potential risk of illness from food poisoning. The majority of unsafe food hygiene practices reported in this review were associated with cross-contamination (Redmond and Griffith 2003).

Another potential risk for foodborne diseases from our study was cross contamination of refrigerated food storage. Behaviours need to be related to keeping foods at safe temperatures and at a proper distance in order to prevent illnesses caused by Bacillus cereus and Clostridium perfringens and Staphylococcu aureus (Hillers et al. 2003).

We also found that many participants believed it was not necessary to clean and disinfect cutting boards between preparing different foods. In fact they reported that the same cutting board was used for the preparation of raw and cooked food without cleansing the cutting board with soap between uses. Furthermore, they were more likely to use wooden cutting boards, thus increasing the potential risk of cross-contamination. A large number did not believe it was necessary to wash their hands after handling raw meat, poultry or fish. These behaviours are associated with pathogens like Salmonella spp., Campylobacter spp, Listeria spp, Escherichia coli O157:H7 and Yersinia enterocolitica (De Giusti et al. 2007; Hillers et al. 2003; Oldfield 2001; Redmond and Griffith 2003; Scott 2001).

The survey found that some individuals consumed raw foods which facilitates the toxic abilities of foodborne pathogens in which adequate cooking is effective towards killing such pathogens. Many outbreaks of Escherichia coli O157:H7 infection have been associated with the consumption of undercooked beef, while an invasive Listeria monocytogenes infection has been linked to undercooked hot dogs (Meng and Doyle 1998; Oldfield 2001).

Most food safety surveys report that a high percentage of individuals, responsible for preparing meals for themselves and other family members, have not been properly informed about food safety procedures, especially towards health risks during preparation in the home (Angelillo et al. 2001; Redmond and Griffith 2003). Our findings are in accordance with other national and international studies (Angelillo et al. 2001; Hillers et al. 2003; Oldfield 2001; Scott 2001; Unusan 2007), reflecting a misperception on the risk of contracting foodborne illnesses in the home which remains a critical link for preventing foodborne diseases. Furthermore, our findings confirm that the home environment completes the food safety and food chain pathway and thus, represents an important site for the 
spread of pathogens responsible for foodborne diseases. This information highlights the lack of knowledge and inadequate behaviours that consumers adopt during food purchase, storage and preparation. Information and educational programs should not be limited to appearance when buying a safe food product.

At the moment, it is unlikely that domestic food handling will reach the same level as food safety control in food industry preparation. However, overall safety procedures of food handling, storage and preparation needs to be indicated to consumers. The use of brochures at supermarkets would be useful to underline the danger of the growth of micro-organisms and their link to inappropriate practices including simple guidelines for proper food purchase, preparation, cooking, and storage, which would further reduce such risk. Another simple possibility would be to print websites dedicated to basic concepts of food safety in the home environment directly on grocery bags (e.g. www.eufic.org, www.ifh-homehygiene.org), or the WHO Five Keys to Safer Food (World Health Organization 2009). As suggested by previous studies, media campaigns could be employed because "Media campaigns could be an excellent opportunity for this aim because such information will be received by a large number of consumers even in the home" (Miles et al. 2004; Unusan 2007). Although our results may not be generalized to the entire Italian population, further studies will be necessary among other groups of consumers in different geographical areas.

\section{Conclusion}

The majority of unsafe food hygiene practices observed in this study were associated with lack of knowledge underlining the important need to increase food safety awareness of Italian consumers. The best way to practice food safety is to be well-informed. At the moment, in Italy, food science or the fundamentals of food hygiene are not taught sufficiently in schools, the ideal place to begin educational interventions and the above results reinforce the need to provide rules and procedures to guide the consumers who are equally responsible as food industry professionals on ensuring food safety in the home. The established foodsafety management system (e.g. HACCP, GHP, GMP) ensures food safety throughout the entire food chain "from farm to table", but needs to adapt additional measures in order to guarantee correct hygiene and food safety in the home.

Conflict of interest The authors declared that they have no conflict of interests.
Open Access This article is distributed under the terms of the Creative Commons Attribution Noncommercial License which permits any noncommercial use, distribution, and reproduction in any medium, provided the original author(s) and source are credited.

\section{References}

Adak GK, Meakins SM, Yip H, Lopman BA, O’Brien SJ (2005) Disease risks from foods: England and Wales, 1996-2000. Emerg Infect Dis 11:365-372

Angelillo IF, Foresta MR, Scozzafava C, Pavia M (2001) Consumers and foodborne diseases: knowledge, attitudes and reported behavior in one region of Italy. Int J Food Microbiol 64:161166. doi:1016/S0168-1605(00)00451-7 http://periodici.caspur. it:3131/pdflinks/11020117510223896.pdf. Cited 10 April 2010

Anklam E, Battaglia R (2001) Food analysis and consumer protection. Trends Food Sci Technol 12:197-202. doi:10.1016/S0924-2244 (01)00071-1

Buzby JC, Roberts T (2009) The economics of enteric infections: human foodborne disease costs. Gastroenterology 136:18511862. doi:10.1053/j.gastro.2009.01.074

Comodo N, Nastasi A, Bonaccorsi G, Barbuti S, Lo Palco PL, Bonanni P, Poli A, Paladini A, Peracca L, Bussotti A, Liverani L (2000) Presente e futuro delle infezioni in ambiente domestico in Italia. Ann Ig 12:233-237

De Giusti M, De Medici D, Tufi D, Marzuillo C, Boccia A (2007) Epidemiology of emerging foodborne pathogens. Ital J Public Health 4:24-31

Doménech E, Escriche I, Martorell S (2007) Quantification of risks to consumers' health and to company's incomes due to failures in food safety. Food Control 18:1419-1427. doi:10.1016/j.food cont.2006.10.005

Fara GM, Proietti C (2000) Il rischio infettivo in Italia oggi: il ruolo dell'ambiente domestico. Ann Ig 12:205-210

Faustini A, Giorni Rossi P, Peducci CA, Food borne Outbreak Control Teams (2003) Outbreaks of food borne diseases in the Lazio region, Italy: the results of epidemiological field investigations. Eur J Epidemiol 18:699-702. doi:10.1023/A:1024884416468

Griffith C, Worsfold D, Mitchell R (1998) Food preparation, risk communication and the consumer. Food Control 9:225-232. doi:10.1016/S0956-7135(98)00003-6

Grunert KG (2002) Current issues in the understanding of consumer food choice. Trends Food Sci Technol 13:275-285. doi:10.1016/ S0924-2244(02)00137-1

Hillers NV, Medeiros L, Kendall P, Chen G, Di Mascola S (2003) Consumer food-handling behaviors associated with prevention of 13 foodborne illnesses. J Food Prot 66:1893-1899

Hoffman RE, Greenblatt N, Matyas BT, Sharp DJ, Esteban E, Hodge K, Liang A (2005) Capacity of state and territorial health agencies to prevent foodborne illness. Emerg Infect Dis 11:11-16

International Commission on Microbiological Specifications for Foods (ICMSF) (2006) Use of epidemiologic data to measure the impact of food safety control programs. Food Control 17:825-837. doi:10.1016/j.foodcont.2005.05.010

Istituto Superiore di Sanità (2003) Foodborne diseases: technicalinformative support for health operators and consumers (in Italian). Rapporti ISTISAN 03/3, ISS, Rome, 64 pp. http:// www.iss.it/binary/publ/publi/0303.1109071669.pdf. Cited 10 April 2010

Istituto Superiore di Sanità. (2006) Safe food in domestic environment: goals and recommendations for surveillance and prevention of foodborne diseases (in Italian). Rapporti ISTISAN 06/27, ISS, Rome, 38 pp http://www.iss.it/binary/publ/cont/06-27\% 20WEB.1161778307.pdf. Cited 10 April 2010 
Istituto Superiore di Sanità (2007) VI National Workshop Enter-net Italia. Surveillance system of enteric infections. Foodborne infections: surveillance and control (in Italian). ISTISAN Congressi 07/C1, Rome, 17-18 May 2007. http://www.iss.it/binary/publ/cont/03935620_2007_I 07_C1.1178704485.pdf. cited 10 April 2010

Kagan LJ, Aiello A, Larson E (2002) The role of the home environment in the transmission of infectious diseases. J Community Health 27:247-267. doi:10.1023/A:1016378226861

Kim BR (2009) Meeting consumer concerns for food safety in South Korea: the importance of food safety and ethics in a globalizing market. J Agric Environ Ethics 22:141-152. doi:10.1007/s10806008-9130-9

Meng J, Doyle MP (1998) Emerging and evolving microbial foodborne pathogens. Bull Inst Pasteur 96:151-163. doi:10.1016/S0020-2452(98)80010-9

Meng J, Doyle MP (2002) Introduction: microbiological food safety. Microbes Infec 4:395-397. doi:10.1016/S1286-4579(02)01552-6

Miles S, Brennan M, Kuznesof S, Ness M, Ritson C, Frewer LJ (2004) Public worry about specific food safety issues. Br Food J 106:9-22. doi:10.1108/00070700410515172

Oldfield EC (2001) Emerging foodborne pathogens: keeping your patients and your families safe. Rev Gastroenterol Disord 1:177-178

Redmond EC, Griffith CJ (2003) Consumer food handling in the home: a review of food safety study. J Food Prot 66:130-161
Schlund J (2002) New directions in foodborne disease prevention. Int J Food Microbiol 78:3-17. doi:10.1016/S0168-1605(02)00234-9

Scott E (2001) Developing a rational approach to hygiene in the domestic setting. J Infect 43:45-49. http://www.ncbi.nlm.nih. gov/pmc/articles/PMC2094945/?tool=pubmed. Cited 10 April 2010

Tauxe RV (2002) Emerging foodborne pathogens. Int J Food Microbiol 78:31-41. doi:10.1016/S0168-1605(02)00232-5

Tirado C, Schmidt K (2001) WHO surveillance programme for control of foodborne infections and intoxications: preliminary results and trends across greater Europe. J Infect 43:80-84

Toyofuku H (2006) Harmonization of international risk assessment protocol. Mar Pollut Bull 53:579-590. doi:10.1016/j.marpol bul.2006.08.008

Unusan N (2007) Consumer food safety knowledge and practices in the home in Turkey. Food Control 18:45-51. doi:10.1016/j. foodcont.2005.08.006

Verbeke W, Frewer LJ, Scholderer J, De Brabander H (2007) Why consumers behave as they do with respect to food safety and risk information. Analytica Chim Acta 586:2-7. doi:10.1016/j. aca.2006.07.065

World Health Organization (2009) Prevention of foodborne disease: five keys to safe food. http://www.who.int/foodsafety/publica tions/consumer/manual_keys.pdf. Cited 10 April 2010 